\title{
MODALIDAD EPISTÉMICA Y SENTIDO DEL OLFATO: LA EVIDENCIALIDAD DEL VERBO OLER
}

\author{
JoRge FERnÁNDEZ JAÉN \\ Universidad de Alicante \\ Jorge.Fernandez@ua.es
}

\begin{abstract}
Resumen
En este trabajo se presenta un análisis del verbo oler realizado con las herramientas teóricas de la lingüística cognitiva y de la teoría pragmática de la modalidad. Por un lado, intentaremos demostrar que el comportamiento sintáctico-semantico de este verbo refleja icónicamente las propiedades olfativas del ser humano, hecho que reforzaría la tesis cognitivista de que el lenguaje está corporeizado. Por otra parte defenderemos que debido a que la información que proporciona el olfato es muy vaga e imprecisa, el verbo oler se caracteriza por mostrar una baja modalidad epistémica, incluso cuando expresa percepciones directas.

PALABRAS CLAVE: lenguaje corporeizado, verbos de percepción, modalidad epistémica.
\end{abstract}

\begin{abstract}
This article analyses the Spanish verb oler with the tools developed both by Cognitive Linguistics and by pragmatic theory of modality. On the one hand, it will be shown that the syntactic-semantic patterns of this verb iconically reflect the smelling abilities of human being, which will support the cognitive postulate that language is embodied. On the other, it is explained that since the information carried out by smelling is so vague, the verb oler is characterized by displaying a low epistemic modality, even when it conveys direct perceptions.

KEY WORDS: embodied language, perception verbs, epistemic modality.
\end{abstract}

\section{Introducción}

Desde la Antigua Grecia, numerosos filósofos han estudiado la capacidad lingüística de un modo objetivista, como si el lenguaje, ese increíble logro evolutivo del Homo sapiens, fuera una especie de herramienta perfecta compuesta por piezas discretas cuya función dominante consistiera en permitir la comunicación entre los hombres. Esta imagen ideal de la facultad lingüística, caracterizada por su descarnado inmanentismo, ha perdurado siglos en el marco de la filosofía, y llegó al siglo XX con gran intensidad. Tanto es así que esta visión del lenguaje se encuentra en los paradigmas lingüísticos estructuralista y generativista; para estas dos escuelas, aunque por razones distintas, el lenguaje constituye un sistema casi perfecto, en el que el punto de vista del hablante (pensamiento subjetivo) y el contexto de uso (información social y pragmática) carecen de importancia. Así, el lenguaje se vuelve una maquinaria muy precisa de la que se sirven para múltiples fines las distintas comunidades de habla, pero sin intervenir decisivamente en su diseño o potencial evolución.

No obstante, en las últimas décadas del siglo XX la situación ha cambiado notablemente con la aparición de la pragmática y de la lingüística cognitiva. Estas dos nuevas perspectivas lingüísticas superan la visión objetivista anterior y estudian el lenguaje de un modo multidimensional, teniendo en cuenta factores contextuales, biológicos, cogni- 
tivos o culturales. Además, la lingüística cognitiva ha asumido que la unidad de análisis debe ser la construcción, no las unidades léxicas aisladas e independientes, ya que hablar presupone establecer relaciones conceptuales entre estructuras sintácticas e imágenes mentales adquiridas experiencialmente, relaciones que pautan la creación del significado lingüístico entendido como una conceptualización de la realidad ${ }^{1}$. Así, puede defenderse que el lenguaje está corporeizado, ya que el contacto con el mundo que sirve de estímulo para el diseño lingüístico se produce siempre a partir del cuerpo, referencia básica y recurrente (Johnson, 1987).

En este trabajo nos proponemos estudiar el verbo oler teniendo en cuenta tanto los factores pragmáticos que están asociados a este verbo como su particular comportamiento sintáctico-semántico. Más concretamente, vamos a desarrollar un análisis de oler utilizando la teoría pragmática de la modalidad epistémica (es decir, el punto de vista del hablante en lo que a certeza en su conocimiento se refiere) e intentaremos demostrar que el comportamiento de este verbo se aleja del de otros verbos de percepción física como ver u oír. También mostraremos cuáles son las principales construcciones sintácticas de oler y sus significados prototípicos, lo que nos permitirá comprobar que, en un marco cognitivista, los valores pragmáticos (modalidad) y los elementos sintáctico-semánticos (conceptualización) forman un continuo en el que los aspectos cognitivos, psicológicos y gramaticales se influyen mutuamente.

\section{Modalidad epistémica y evidencialidad}

La modalidad es un concepto que alude a la actitud o subjetividad del hablante en relación al discurso linguístico. Se trata de un fenómeno que ha sido ampliamente estudiado y por el que se han interesado diversas disciplinas científicas, como la lógica, la psicología, la semiótica, la sintaxis o la semántica formal (Ruiz Gurillo, 2006: 57). Desde un punto de vista pragmático, el problema de la modalidad lingüística renace con especial intensidad porque es precisamente en el uso real y cotidiano del lenguaje en el que hace mayor acto de presencia el punto de vista de los hablantes.

En todo acto comunicativo, un determinado locutor puede dirigir su subjetividad hacia dos elementos; por un lado, puede proyectar su punto de vista hacia su interlocutor (el oyente) y por otro, puede dirigir su percepción de las cosas hacia el código lingüístico (el enunciado). Cuando la subjetividad se orienta hacia el oyente hablamos de modalidades de la enunciación, mientras que cuando se proyecta hacia el enunciado aparecen las modalidades del enunciado (Otaola, 1988; Ruiz Gurillo, 2006: 57-67).

Las modalidades de la enunciación son las responsables de que existan los contenidos básicos en términos comunicativos que codifican las oraciones. Así tendríamos, prototípicamente, modalidades de la enunciación declarativa, interrogativa, imperativa, exclamativa, dubitativa y desiderativa (Otaola, 1988: 101). El hablante codifica su punto de vista y sus necesidades pragmáticas de un determinado modo para transmitirle a su receptor

1 La lingüística cognitiva de Langacker $(1987,1991)$ no es la única perspectiva que trabaja a partir del concepto de construcción; también se da esta hipótesis en la Gramática de Construcciones de Goldberg (1995) o en la Gramática de Construcción Radical de Croft (2001). 
un mensaje específico, como que desea darle una información (enunciación declarativa), que desea obtener una información (enunciación interrogativa) o que desea que él haga una determinada acción (enunciación imperativa). Como es bien sabido, no existe una relación causal y biunívoca entre forma proposicional y modalidad de la enunciación, ya que una misma modalidad se puede expresar sintácticamente de múltiples maneras. Un ejemplo clásico de ello lo tenemos en la modalidad imperativa que puede mostrarse de un modo más o menos directo en función de lo cortés que desee ser el hablante (Ruiz Gurillo, 2006: 60-61)2.

En cuanto a las modalidades del enunciado, las que nos interesan en este trabajo, se ha venido hablando en la bibliografía especializada de tres tipos básicos: si el hablante cree que su enunciado es verdadero tenemos modalidad epistémica, si cree que es probable modalidad alética y si considera que es necesario modalidad deóntica (Otaola, 1988: 102). Como vemos, el locutor al emitir su mensaje no trasmite únicamente una información pragmática dirigida al oyente con la intención de que entienda su enunciado, sino que también muestra su punto de vista con respecto al grado de certeza o pertinencia de lo que dice. De este modo, en el discurso lingüístico se hallan una serie de marcas que indican qué juicio de valor posee el hablante acerca de la validez o necesidad de sus propias enunciaciones.

Las modalidades epistémica y alética han sido objeto de discusión teórica ya que en opinión de algunos autores entre ellas no se establece una distinción discreta sino una diferenciación continua o gradual; entre un conocimiento totalmente cierto y uno dudoso o contingente se dan diferencias de grado, puesto que el conocimiento no se concibe habitualmente en términos absolutos. Por ello, resulta más operativo seguir la concepción propuesta por Bybee, Perkins y Pagliuca (1994), según la cual debemos hablar tan sólo de modalidad epistémica, entendida como un continuo con dos polos opuestos, el de la máxima certeza y el de la máxima duda, polos entre los cuales se extendería todo un conjunto de hipótesis y probabilidades. De este modo, la modalidad epistémica se ocuparía del nivel de conocimiento del hablante con respecto a lo que dice (sea mucho, poco o total) y se opondría a la modalidad deóntica (lo que debe ser o suceder).

Dentro de la modalidad epistémica cabe destacar la existencia de un fenómeno muy interesante que ha despertado el interés científico de numerosos lingüistas en los últimos años: nos referimos a la evidencialidad lingüística. La evidencialidad hace referencia a la fuente de información del hablante; si la fuente es fiable, la modalidad epistémica del enunciado será alta o cierta, mientras que si la fuente es dudosa, la modalidad epistémica se caracterizará por su baja dosis de certeza. Consecuentemente, la teoría de la evidencialidad se encargará de estudiar las diferentes evidencias o fuentes de conocimiento, y su expresión lingüística estará formada por los evidenciales, que son las distintas huellas gramaticales (verbos, marcadores discursivos, etc.) que señalan cuál es el grado de fiabilidad de la fuente de información (Ruiz Gurillo, 2006: 71-72).

Le debemos a Willett (1988) la primera clasificación lingüística de los tipos de evidencia, clasificación perfeccionada por Plungian (2001) y por Dendale y Tasmowski (2001). A

2 Los actos de habla indirectos del tipo ¿Puedes acercarme el libro?, en lugar del imperativo Acércame el libro son buena muestra de este fenómeno pragmático. 
continuación ofrecemos dicha clasificación acompañada con ejemplos de la lengua española, tal y como la presenta Ruiz Gurillo (2006: 72):

\begin{tabular}{|c|c|c|c|c|}
\hline & Directa & atestiguada & $\begin{array}{l}\text { visual } \\
\text { escuchada } \\
\text { percibida por } \\
\text { otros sentidos }\end{array}$ & $\begin{array}{l}\text { claro } \\
\text { evidentemente } \\
\text { por supuesto }\end{array}$ \\
\hline $\begin{array}{l}\text { Tipos } \\
\text { de }\end{array}$ & & & & \\
\hline evidencia & & reproducida & $\begin{array}{l}\text { de segunda mano } \\
\text { según dicen } \\
\text { de tercera mano } \\
\text { del folclore }\end{array}$ & $\begin{array}{l}\text { al parecer } \\
\text { por lo visto }\end{array}$ \\
\hline & & inferida & $\begin{array}{l}\text { como un resultado } \\
\text { según se deduce } \\
\text { como un razonamiento }\end{array}$ & a mi entender \\
\hline
\end{tabular}

Tabla 1. Tipos de evidencia.

Como se aprecia en este esquema, la primera diferenciación tiene que ver con el hecho de que la fuente de información sea una experiencia directa o una información indirecta. Si una información se obtiene porque se ha presenciado físicamente a través de los sentidos (fundamentalmente por la vista o el oído) se caracterizará por ser muy fiable porque ser testigo presencial de cualquier hecho garantiza su mayor comprensión y conocimiento. De este modo, marcadores discursivos como claro o evidentemente indican que el locutor está totalmente seguro de aquello que enuncia ${ }^{3}$.

Sin embargo, cuando la información no se obtiene de un modo directo, su grado de certeza disminuye y la modalidad lingüística se va deslizando progresivamente desde un nivel de modalidad epistémica alto a niveles cada vez más dudosos. Así, se distingue entre fuentes reproducidas y fuentes inferidas. Las primeras tienen que ver con la información que recibimos por otras personas; en estos casos, la fiabilidad es menor ya que es otro el sujeto que ha presenciado o escuchado los hechos, lo que desplaza el punto de vista y lo

3 Que el adjetivo claro y el adverbio evidentemente (formado a partir del adjetivo evidente) sean evidenciales de evidencia directa no resulta extraño en absoluto teniendo en cuenta su significado. Claro suele vincularse metafóricamente con el conocimiento en virtud de la metáfora VER ES CONOCER que examinaremos más tarde; para poder ver hace falta luz y claridad, por lo que en un plano abstracto la claridad también se relaciona con la ausencia de dificultades para obtener un conocimiento. Por su parte, evidente procede del adjetivo latino evidens que significaba, entre otras cosas, visible (que puede verse $\mathrm{y}$, por tanto, conocerse). 
sitúa en un enunciador distinto del que habla. De este modo, el locutor que cita al otro (la fuente reproducida) ya no es responsable de la veracidad de los datos. Marcadores como al parecer o por lo visto ${ }^{4}$ son buena muestra de este tipo de evidencia.

Finalmente, los hablantes pueden poseer un conocimiento de las cosas de naturaleza más hipotética. El contacto con la realidad ofrece constantemente pistas e indicios de acontecimientos muy variados, gracias a lo cual los hablantes pueden inferir y metarrepresentar cosas que han sucedido y cómo han sucedido. De este modo, el puro razonamiento intelectivo puede ser una fuente de información, si bien una fuente subjetiva más dificil de confirmar. Marcadores como a mi entender o verbos modales como creer, suponer o imaginar, son buenos ejemplos del carácter especulativo de numerosos enunciados.

Otra cuestión interesante tiene que ver con el grado de gramaticalización y lexicalización de los evidenciales en las distintas lenguas. En opinión de Lazard (2001) el nivel de gramaticalización de la evidencialidad es gradual; de este modo, algunas lenguas tendrán un sistema de evidenciales totalmente gramaticalizado, otras utilizarán únicamente determinadas palabras y estructuras convencionalizadas para expresar información sobre el nivel de certeza epistémica (como marcadores discursivos o unidades fraseológicas) y por último habría lenguas en las que la evidencialidad vendría siempre activada por términos polisémicos y polivalentes no especializados tan sólo en expresar modalidad.

Lo más frecuente en casi todas las lenguas es la expresión no gramaticalizada de la evidencialidad; aunque es habitual que las lenguas posean marcadores discursivos que codifican información sobre la fuente del conocimiento y adverbios y otros elementos que son capaces de funcionar como evidenciales si el contexto lo requiere, lo cierto es que la categoría gramatical de la evidencialidad es muy extraña. Aun así, existen lenguas que la poseen y tienen morfemas especializados en indicar si el enunciado es más o menos fiable. Por ejemplo, esta categoría se encuentra en ciertas lenguas balcánicas, en algunas tibetobirmanas, en japonés clásico y en numerosas lenguas americanas, sobre todo de América del Sur (Moure, 2001: 142). En estos casos, la codificación morfológica de la evidencialidad suele limitarse a indicar si la información puede o no verse con los ojos: si se puede ver será siempre más fiable que si no es perceptible visualmente.

Con todo, existe una lengua cuya gramaticalización de la evidencialidad es muy sofisticada; se trata de la lengua Tuyuca, hablada en la ribera del río Vaupés, entre Colombia y Brasil. Según ha estudiado Barnes (1984), esta lengua posee un sistema de sufijos que se añaden a los verbos para indicar la exactitud del enunciado. Así, en Tuyuca existen cinco niveles de certeza: visual, no-visual, aparente, informado y asumido. Consideremos los siguientes ejemplos (Barnes, 1984: 257):

(1) diiga apé-wi

(2) diiga apé-ti

(3) diiga apé-yi

(4) díga apé-yigi

(5) díiga apé-hiyi

4 Nótese que en por lo visto se emplea el verbo ver como prueba de una percepción directa, sólo que se trata de una percepción que no ha tenido el enunciador, sino otra persona. Para un detallado análisis de este marcador véase Ruiz Gurillo (2006: 75-78). 
Todas estas oraciones en Tuyuca significan lo mismo: Él ha jugado al fútbol. Sin embargo el grado de modalidad epistémica es diferente. La oración de (1) indica que el sujeto vio la escena y está seguro de que ese hecho es verdadero. La certeza en el ejemplo (2) también es muy alta ya que el sujeto ha escuchado personalmente el ruido del partido y al propio jugador, aunque no ha llegado a verlo. En (3) la certeza disminuye un poco: el sujeto ha visto físicamente evidencias de que se ha producido el juego (las zapatillas de fútbol, la ropa, etc.) pero no ha visto ni oído nada del partido. Por otro lado, la modalidad en (4) señala que el locutor de la frase ha recibido la información de otra persona (fuente indirecta), por lo que no puede asegurar que el hecho se produjera. Finalmente, la oración de (5) codifica la mínima certeza; en este caso el locutor lanza una hipótesis acerca de lo que ha debido de suceder basada solamente en inferencias (no están las zapatillas de fútbol, no hay nadie en casa, etc.). Lo interesante es que toda esta información relacionada con la fuente de conocimiento se encuentra en una serie de sufijos (-wi, -ti, -yi, -yigi, -hiyi) especializados únicamente en verbalizar el nivel de evidencialidad.

Por lo tanto, comprobamos que la categoría de la evidencialidad en Tuyuca es muy icónica puesto que cumple con el principio del isomorfismo lingüístico que considera que a cada contenido semántico le corresponde una forma gramatical específica (Haiman, 1980, 1985; Givón, 1991). No obstante, como señala acertadamente Moure (2001: 143), un nivel tan alto de iconicidad en la categoría gramatical de la evidencialidad no resulta muy operativo ya que complica en exceso el discurso y la comunicación. Piénsese, por ejemplo, en el lenguaje político o en la expresión de los sentimientos; la utilización en esos registros de evidenciales tan gramaticalizados resulta problemática por lo que no resulta extraño que la mayoría de lenguas, y el español entre ellas, hayan simplificado sus evidenciales y empleen términos más generales para expresar esos contenidos, otorgándole un mayor peso específico al contexto de habla como elemento discriminador ${ }^{5}$.

En definitiva, el lenguaje está constantemente influido por la subjetividad de los hablantes y por las condiciones extralingüísticas hasta el punto de que incluso el tipo de fuente de información de que se sirve el locutor en el momento de trasmitir determinados contenidos puede ser recuperado a través de la morfosintaxis.

\section{Percepción física y conocimiento}

Como hemos comprobado en el apartado anterior, se suele relacionar el conocimiento fiable con la percepción física; utilizar los sentidos corporales (vista, oído, etc.) en un determinado contexto presupone obtener un conocimiento inmediato y no desvirtuado de las cosas, lo que eleva el nivel de modalidad epistémica. Esta circunstancia viene reforzada también por la biología, puesto que la necesidad de sobrevivir en el medio es una máxima de la selección natural de Darwin, y no cabe duda de que los distintos sentidos físicos cons-

5 El hecho de que las lenguas tiendan a hacer menos icónico su sistema de evidenciales parece confirmar la hipótesis de Haiman (1980) según la cual existe una relación inversamente proporcional entre la elaboración léxica de una lengua y su nivel de iconicidad; de este modo, cuanto más complejo es el léxico (en términos conceptuales y semánticos) menos icónico es el código lingüístico. Por ejemplo, las lenguas pidgin siempre son más icónicas que las lenguas de las que derivan, de igual modo que las jergas y argots son también mucho más icónicos que los registros más generales. De hecho, incluso el lenguaje infantil va evolucionando desde un nivel de iconicidad mayor (primeros años de vida) hasta un nivel más bajo en la edad adulta (Haiman, 1980: 537). 
tituyen el medio más eficaz para recabar información objetiva del entorno; gracias a ellos las especies alcanzan fines muy necesarios para prosperar, como detectar a los enemigos potenciales, descubrir alimentos o encontrar a una pareja. Así, en cada especie los sentidos evolucionan de un modo diferente y se adecuan a sus concretas necesidades. Por ejemplo, los tiburones han desarrollado hasta siete sentidos físicos, gracias a los cuales pueden detectar todo tipo de movimientos en el agua; además, también han desarrollado un sentido especial para percibir impulsos eléctricos, con lo que son capaces de cazar presas que se encuentran ocultas bajo la arena. En cuanto a su olfato, es tan sumamente agudo que les permite descubrir una mínima cantidad de sangre (y por ello, a una posible presa) a mucha distancia. Por todo ello, se puede afirmar que los escualos siguen poblando los océanos gracias a que han sido capaces de adaptar sus sentidos físicos a sus necesidades vitales; no disponen de una vista precisa ni de un buen oído, pero son unos excelentes cazadores gracias a su tacto y olfato.

La evolución del ser humano no supone una excepción en este sentido, puesto que también nuestra especie ha ido modificando sus sistemas de percepción según sus necesidades. Los primates más antiguos de los que tenemos noticia (como el dryopithecus, que vivió en Europa en el período Mioceno) eran insectívoros que vivían en los árboles, y ya para ellos era más importante el sentido de la vista que el del olfato para sobrevivir, pues era con ese sentido con el que capturaban a sus presas y pasaban con facilidad de una rama a otra. Con el tiempo, la actividad de los primates pasó de ser nocturna a ser diurna, con lo que la vista mejoró todavía más; en el caso concreto del Homo sapiens, sus ojos se han ido desplazando progresivamente de una posición lateral en la cabeza a una posición frontal, que es la que nos permite a los hombres modernos la visión binocular (los dos ojos apuntando al mismo objeto) responsable de la percepción estereoscópica de las imágenes, forma de visión gracias a la cual captamos mejor las distancias y la forma de las cosas (Mosterín, 2006: 107-112).

Este predominio de la vista en nuestra especie se percibe en multitud de aspectos culturales y antropológicos (arte pictórico, iconografía religiosa, etc.) y ha sido ensalzado por el pensamiento científico desde los orígenes de la filosofía. Desde un punto de vista lingüístico, la jerarquía de los sentidos (de la vista hasta los secundarios olfato y gusto) también se ha descrito, y existen numerosos fenómenos que hacen pensar que los elementos léxicos-semánticos vinculados a la percepción física tienen carácter universal.

E. Sweetser propuso en 1990 un conocido conjunto de cambios semánticos en lenguas Indoeuropeas relacionados con la percepción física que ha sido aceptado como válido en casi todas las lenguas. Esquematizamos dichos universales a continuación (Sweetser, 1990: 38):

\begin{tabular}{|l|l|}
\hline SENTIDO FÍSICO & VALOR METAFÓRICO Y COGNITIVO \\
\hline Vista & $\begin{array}{l}\text { Conocimiento, imágenes mentales, supervisión, control, manipulación } \\
\text { mental. }\end{array}$ \\
\hline Oído & \begin{tabular}{l} 
Conocimiento, obediencia. \\
\hline Tacto
\end{tabular} \\
\hline Olfato y gusto & Emoción, subjetividad. \\
\hline
\end{tabular}

Tabla 2. Universales semánticos de la percepción. 
Como se aprecia en este cuadro, la vista es el sentido que más fácilmente se vincula al conocimiento (además de a otros dominios como la vigilancia y el control), algo que favorece la existencia de la metáfora VER ES CONOCER. Esta metáfora se da en casi todas las lenguas del mundo y posibilita que habitualmente los verbos de percepción visual posean significados epistémicos, como saber, opinar o conocer (Danesi, 1985, 1990). Basta para comprobarlo con observar ejemplos como estos:

(6) Acabo de ver la solución del problema.

(7) Juan no ve con buenos ojos esas propuestas económicas.

(8) He visto en su expresión que me está mintiendo.

En todos estos ejemplos encontramos el verbo ver utilizado como evidencial, ya sea con una alta modalidad epistémica (ejemplos (6) y (8)) o con una modalidad más subjetiva, próxima a la opinión (ejemplo (7)).

Por su parte, el sentido auditivo también se relaciona con el conocimiento, si bien se trata de un conocimiento menos fiable que el de la vista, ya que la visión es más objetiva e inmediata. Aun así, lenguas como el hebreo tienen verbos de percepción auditiva que expresan fácilmente contenidos epistémicos (Luque Durán, 2001: 191). Otro ejemplo muy importante de expresión lingüística del conocimiento a partir del sentido de la audición lo ofrecen ciertas lenguas australianas. Como demostraron Evans y Wilkins (2000), para muchas tribus aborígenes de Australia es el oído el sentido más importante y el que mejor expresa el conocimiento. Por tanto, vemos que también es frecuente la metáfora OÍR ES CONOCER ${ }^{6}$. Pero además de este valor modal, los verbos de percepción auditiva también tienden a desarrollar significados como obedecer y responder, puesto que escuchar algo y comprenderlo suele comportar una determinada reacción. Observemos los siguientes ejemplos:

(9) ¿Es que no me has oído?

(10) Maria tiene que escuchar más a su jefe.

Estos dos enunciados ejemplifican el significado que estamos comentando. La interrogación de (9) podría muy bien dirigirse a alguien que ha desobedecido un mandato o que aún no ha realizado una determinado tarea, siendo el verbo oír el encargado de expresar la obediencia pretendida por el emisor. En (10) el verbo escuchar se emplea con un significado idéntico al de obedecer, contenido reforzado por el uso de la perífrasis de obligación tener que + infinitivo, de marcada modalidad deóntica.

Por su parte, los sentidos del tacto, olfato y gusto, también llamados sentidos inferiores, muy raramente expresan contenido epistémico lo que los distingue de los sentidos superiores (vista y oído). Las metáforas producidas por los lexemas asociados a estos sentidos se relacionan con un tipo de subjetividad fuertemente emocional, en la que se encuentran los sentimientos amorosos, los gustos, los deseos, los miedos o los recuerdos. Ya Platón y Aristóteles pensaban que con esos sentidos no podía alcanzarse ningún conocimiento del

6 Para un análisis más detallado de la expresión lingüística del conocimiento a través del sentido de la audición véase el trabajo de Ibarretxe-Antuñano (2008). 
mundo, sino tan sólo percepciones interiores y difusas; las sensaciones táctiles, los olores y los sabores no muestran cómo son las cosas en realidad, sino tan sólo cómo las experimentamos con nuestro propio cuerpo de forma individual. Frente a eso, la vista y el oído perciben los fenómenos del mundo a distancia, de modo que se produce una nítida separación entre sujeto y objeto, lo que asegura que el perceptor puede obtener una información fiable, no alterada por sus sentidos más inexactos (Korsmeyer, 2002: 27-61).

A pesar de que las metáforas propuestas por Sweetser son muy frecuentes y aparecen en una gran cantidad de lenguas y con una estructura conceptual casi idéntica, también se han documentado algunas excepciones dentro de la expresión lingüística de la jerarquía de los sentidos, excepciones en las que sentidos inferiores (tacto, olfato y gusto) ocupan la posición más preeminente. Por ejemplo, en la cultura Tzotzil de México se considera que la fuerza del cosmos procede del calor, por lo que es el tacto el sentido más valorado en esa cultura (Classen, 1993). Los Ongee, nativos de las Islas Andamán situadas en el Océano Índico, establecen los parámetros de su vida utilizando los olores (Classen, Howes y Synnott, 1994). Por último, cabe mencionar el caso de la lengua papuásica Kobon, en la que no existen verbos de percepción claramente lexicalizados, sino tan sólo un verbo genérico que se utiliza para todas las percepciones (Viberg, 1984).

Como vemos, aunque la mayoría de las lenguas lexicalizan la percepción de un modo similar, existen suficientes excepciones como para replantear el problema, puesto que cualquier sentido puede ocupar el puesto más prominente en la jerarquía y desarrollar así valores fuertemente epistémicos. Por ello, en un trabajo reciente que revisa todas las excepciones a la jerarquía tradicional de los verbos de percepción, I. Ibarretxe-Antuñano (2008) ha propuesto subsumir la metáfora VER ES CONOCER dentro de una más general: PERCIBIR ES CONOCER. De este modo, se enfatiza el hecho de que los sentidos físicos son la fuente primaria del conocimiento del mundo, pero sin concretar cuál es el sentido implicado en dicho conocimiento. De este modo, como resalta esta investigadora, se comprueba que más allá de las limitaciones que la biología le impone al lenguaje (es más importante la vista para sobrevivir que el tacto o el olfato), hay factores culturales y antropológicos que hacen que determinadas comunidades lingüísticas le otorguen más importancia a un sentido inferior, aunque ello suponga una ligera contradicción, al menos en términos de adaptación darwinista al medio.

\subsection{Propiedades del olfato humano}

De lo anteriormente expuesto se deduce que el sentido del olfato no es el más rentable para el ser humano desde un punto de vista biológico, ya que se trata de un sentido que aporta una información poco eficaz para conocer el mundo y sobrevivir en él. Por ello, aunque algunas comunidades lingüísticas valoren de un modo especialmente intenso este sentido físico y lo sitúen en un lugar privilegiado en su cultura y sociedad, lo cierto es que la mayoría de lenguas poseen una lexicalización del olfato relativamente limitada, sobre todo si se la compara con la de otros sentidos. Las causas por las que la expresión lingüística del olfato es problemática se encuentran en la propia naturaleza fisiológica de este sentido. A continuación examinaremos cuáles son las principales propiedades del olfato humano, lo que nos permitirá comprender con mayor exactitud el comportamiento sintáctico-semántico de oler que presentaremos después. 
E1 olfato humano se caracteriza fundamentalmente por cuatro rasgos: escasa importancia cognitiva, brevedad de la olfacción, vaguedad referencial y falta de control (Fernández Jaén, 2006b). De la primera propiedad ya hemos hablado anteriormente; debido a la particular evolución de los primates en general y de nuestra especie en particular, han sido los sentidos de la vista y del ó́do los que mayor protagonismo han tenido en nuestro contacto con el mundo, en nuestra supervivencia y en nuestro consiguiente desarrollo. Por ello no resulta extraño que los verbos del olfato no suelan vincularse a contenidos intelectivos.

La segunda propiedad es sumamente interesante y ha sido muy discutida en psicología. El ser humano no es capaz de mantener una percepción olfativa durante mucho tiempo puesto que, transcurridos unos pocos minutos, hasta el olor más intenso tiende a desaparecer para cualquier persona. Pensemos en un individuo que entra en una habitación en la que hay un fuerte olor a carne quemada; ese estímulo olfativo será inmediatamente percibido por ese individuo, pero tras unos momentos, no lo notará. De hecho, sólo si abandona la estancia y vuelve a entrar en ella al cabo de unos minutos podrá volver a experimentar esa olfacción. Este fenómeno se denomina adaptación (Matlin y Foley, 1996: 424-426) y demuestra que, a diferencia de otros animales, el Homo sapiens tiene un olfato muy limitado.

El tercer rasgo se asocia al carácter fuertemente subjetivo del sentido del olfato. Para los seres humanos los olores tienen un gran poder de evocación, puesto que con frecuencia nos recuerdan a personas, a lugares, a épocas de nuestra vida o a cualquier otra circunstancia. Ese poder de evocación de los estímulos olfativos entronca directamente con nuestras pasiones más atávicas, lo que explica que en ocasiones un simple olor sirva para hacernos desear algo o para repudiarlo. Pero como contrapartida, nuestro olfato es poco agudo, por lo que nuestros juicios sobre los olores normalmente no sobrepasan la mera apreciación individual; casi nunca sabemos a qué huelen las cosas o de dónde proceden los olores, ni por qué nos gustan o nos disgustan. Por ello, los objetos olfativos son muy difíciles de conocer, frente a la objetividad que caracteriza a los estímulos de los sentidos superiores, y nos limitamos a hacer comentarios subjetivos sobre ellos.

Por último, una característica muy importante del sentido del olfato es la falta de control que caracteriza a las percepciones olfativas. Los olores nos asaltan de forma inesperada e incontrolada debido a que nuestro órgano olfativo, la nariz, siempre está abierto y activo y a que las partículas que trasportan los olores viajan por el aire de manera errática. Por estas razones es muy difícil prever cuándo se và a experimentar una sensación olfativa. Además, esta propiedad permite que el olfato humano funcione en ocasiones como una alarma cognitiva: detectamos de forma involuntaria los olores, lo que facilita el descubrimiento de estímulos desagradables de los que hay que huir (el olor de algo podrido, de un incendio, de una sustancia tóxica, etc.), razón por la cual el olfato sí ha ayudado en nuestra evolución (al señalarnos aquello que era nocivo y peligroso) si bien no del mismo modo que los sentidos superiores.

En definitiva, comprobamos que nuestro sentido del olfato es mucho más limitado que el de otros seres vivos que dependen más de él, aunque eso no significa que no nos proporcione una visión más completa y rica del entorno. 


\section{Oler como verbo de percepción}

En opinión de la lingüística cognitiva, la sintaxis, la semántica y la pragmática están totalmente unidas y no pueden explicarse de forma aislada. En su conjunto forman una conceptualización que representa cómo percibe el mundo el hablante, por lo que cabe suponer que todas las propiedades del olfato que hemos examinado influyen en el comportamiento lingüístico del verbo oler. Pero para entender este comportamiento, antes hay que conocer cuál es el funcionamiento general de los verbos de percepción.

Los verbos de percepción física se encargan de expresar lingüísticamente el contacto con el entorno que se realiza con los cinco sentidos corporales, por lo que habrá verbos de percepción visual, auditiva, táctil, olfativa y gustativa (Fernández Jaén, 2006a). En 1984 el lingüista A. Viberg publicó un trabajo en el que establece una tipología de los verbos de percepción basada en el análisis de numerosas lenguas del mundo, tipología que presentamos a continuación:

Verbos de percepción

1) Verbos de percepción activa

2) Verbos de percepción pura

3) Verbos de percepción copulativa

a) Como capacidad

b) Sujeto-estímulo

Tabla 3. Tipología de los verbos de percepción (Viberg, 1984: 123-124)

Como señala Horno Chéliz (en prensa) esta tipología se fundamenta en la teoría aspectual de los eventos defendida por primera vez en el trabajo clásico de Vendler (1967), y en trabajos posteriores como los de Pustejovsky $(1991,1995)$. De este modo, los verbos de percepción activa representan un evento de actividad, en el que tenemos un sujeto animado (observador o agente) que realiza voluntariamente una acción con alguno de sus órganos perceptivos durante un determinado período de tiempo con el fin de examinar un concreto estímulo. Ejemplos españoles de verbos de percepción activa de diferentes sentidos serían mirar, saborear o acariciar.

Los verbos de percepción pura representan aspectualmente un logro, no una actividad. Por ello en estos casos nos encontramos con un evento de experiencia involuntaria, en el que un sujeto percibe un estímulo sin pretenderlo. Estas percepciones se producen cuando un estímulo alcanza un órgano corporal y dicho órgano lo descifra de forma espontánea, sin que el sujeto pueda evitarlo. Ejemplos de este tipo los tenemos en el verbo sentir y en muchos empleos de ver y oir ${ }^{7}$. Naturalmente, el papel temático del sujeto sintáctico con estos verbos ya no es el de agente u observador sino el de perceptor o paciente (van Valin y LaPolla, 1997; Moreno Cabrera, 2003).

Por último, los verbos de percepción copulativa representan un estado y no estrictamente un evento. Esta posibilidad se subdivide a su vez en dos tipos. Por un lado el verbo de percepción expresa una capacidad sensorial del sujeto, como en la oración María no oye sin su audífono,

7 Los verbos ver y oír pueden expresar tanto percepción activa como percepción pura. Puede verse un análisis sintáctico de este fenómeno en Fernández Jaén (2006a). 
en la que oir representa la capacidad fisiológica de la audición. La otra posibilidad se da cuando el sujeto sintáctico del verbo es el estímulo y no el observador o el perceptor. Ejemplos de este tipo son los que ofrecen oraciones como Desde aqui se ve esa montaña, oración en la que esa montaña es al tiempo el sujeto sintáctico y el estímulo sensorial percibido con la vista.

Todos estos valores de los verbos de percepción se conceptualizan de un modo particular en cada lengua. Por ejemplo, el Swahili dispone de tres verbos de percepción visual para cada uno de los valores, el verbo tazama (percepción activa), el verbo ona (percepción pura) y el verbo onekana (percepción copulativa) (Viberg, 1984: 139), frente a la lengua hindi que cuenta con un único lexema, el verbo dekhna, para expresar las tres modalidades de la visión (Viberg, 1984: 133). Con el resto de sentidos sucede lo mismo. Así, en inglés la audición se expresa con tres verbos, listen to (actividad), hear (logro involuntario) y sound (percepción copulativa), mientras que en quechua los valores auditivos de actividad y logro se lexicalizan con el verbo uyariy, verbo al que se le puede añadir un sufjo para obtener el valor copulativo uyarikuy (Viberg, 1984: 135).

En cuanto a los sentidos del tacto, olfato y gusto, lo más frecuente es que un único lexema desempeñe todos los valores, e incluso hay lenguas en las que un único verbo representa las tres posibilidades (actividad, logro y percepción copulativa) de estos tres sentidos. Por ejemplo, en sueco el verbo känna se utiliza indistintamente para los sentidos del tacto, olfato y' gusto y para todas sus posibilidades sintáctico-semánticas (Viberg, 1984: 138).

A continuación aplicaremos esta tipología al verbo oler con el fin de determinar su naturaleza lingüística y sus principales veriantes sintácticas.

\subsection{Estructura de oler}

En la lengua española oler es el verbo prototípico de la percepción olfativa y codifica las tres posibilidades propuestas por Viberg. Por esta razón, tendremos un uso de oler como verbo de percepción activa, otro uso como verbo de percepción pura y usos como verbo copulativo, tal y como se ejemplifica a continuación:

(11) Luis olió el perfume para decidir cuál regalarle a su novia.

(12) Luis olió el perfume en cuanto se acercó a su vecina.

(13) Luis no puede oler porque está resfriado.

(14) La camisa huele a perfume

En el ejemplo (11) oler funciona como un evento de actividad; Luis es un observador agentivo que examina voluntariamente un objeto oloroso, ejerciendo sobre dicho objeto una acción controlada. Por el contrario, en (12) Luis ya no es un sujeto observador sino un mero perceptor involuntario que detecta un olor porque la fuente de dicho olor se aproxima a él. Por ello, la olfacción que expresa (12) es aspectualmente un logro ingresivo, de duración puntual, frente a lo expresado en (11) que es una acción que tiene más duración en el tiempo.

La oración de (13) es un claro ejemplo de percepción copulativa entendida como capacidad; como es sabido, un resfriado puede anular temporalmente la capacidad de percibir los olores ${ }^{8}$, algo que también se expresa en este caso con el verbo oler.

8 La pérdida del sentido del olfato se denomina anosmia y, aparte de por una infección, se puede producir por un traumatismo encefálico (Matlin y Foley, 1996: 430). 
Por último, en (14) encontramos un ejemplo copulativo en el que el sujeto sintáctico $L a$ camisa constituye el estímulo sensorial o fuente del olor. Esta posibilidad sintáctica posee en español tres variantes (Fernández Jaén, 2006b):

\begin{tabular}{|l|l|}
\hline \multicolumn{1}{|c|}{ Variante } & \multicolumn{1}{c|}{ Ejemplo } \\
\hline a) Sujeto-estímulo + verbo & La comida huele. \\
\hline b) Sujeto-estímulo + verbo + suplemento con $a$ & La cocina huele a cebollas fritas. \\
\hline c) Sujeto-estímulo + verbo + CCM & Este pañuelo huele como el jazmin. \\
\hline
\end{tabular}

Tabla 4. Variantes sintácticas de oler con sujeto-estímulo.

La primera estructura es la más simple puesto que consta únicamente del sujeto ${ }^{9}$ del verbo. No aparece ningún complemento acompañando al núcleo verbal aunque sí es muy frecuente el empleo de algún adverbio que matice si el olor es agradable o no, como bien, mal, estupendamente, etc. Es importante resaltar que en español, como en casi todas las lenguas, cuando se emplea esta estructura y no se especifica lo contrario, oler significa siempre oler mal. Por tanto, en el ejemplo La comida huele, se estaría diciendo que huele de un modo desagradable a menos que se emplee algún sintagma que cancele esa interpretación. En opinión de Boisson (1997) esta tendencia de los verbos de percepción olfativa a expresar que las cosas huelen mal es prácticamente universal, hecho que quizá se deba a la función antropológica del olfato como alarma sensorial que alerta de la presencia de elementos perjudiciales o peligrosos.

Por su parte, las variantes b) y c) añaden un elemento que no aparece en la variante a): un sintagma que especifica cuál es el tipo de olor que reproduce el sujeto-estímulo. En b) el tipo de olor viene representado por un estructura preposicional regida (o suplemento) encabezada por la preposición $a$, mientras que en c) el olor que reproduce el sujeto-estímulo se verbaliza con un Complemento Circunstancial de Modo (CCM) introducido por como. En ambos casos estos sintagmas representan una hipótesis acerca de cuál es el olor percibido; dado que nuestro olfato no es muy agudo, casi nunca estamos seguros de a qué huelen las cosas, por lo que es frecuente que el hablante especule subjetivamente sobre la naturaleza de los olores que recibe.

Por tanto, las variantes b) y c) constituyen una estructura evidencial de modalidad epistémica variable. El suplemento de b) puede indicar una alta certeza o una certeza menor, puesto que en algunas ocasiones el enunciador de la oración estará seguro de cuál es el olor que reproduce el sujeto-estímulo y en otras no lo estará, de manera que la fiabilidad de la información que proporciona el suplemento es relativa y dependerá siempre del contexto. Pero en el caso del CCM de c) la modalidad epistémica disminuye aún más con respecto a b), puesto que en este caso la hipótesis acerca de la fuente del olor se manifiesta con una expresión aproximativa (Ruiz Gurillo, 2006: 98). En efecto, en el habla

9 Es importante señalar que con mucha frecuencia el sujeto sintáctico se elide en todas estas variantes, de manera que sólo permanece el verbo, acompañado o no de complementos (Aqui huele, Huele mucho a cloro, etc.) 
cotidiana damos constantemente informaciones de las que no estamos muy seguros, como al reproducir una cita de otro hablante en un discurso directo. En estos casos, es frecuente que aparezcan marcas del tipo y tal y cual, de no sé que y no sé cuantos, etc., que rebajan la modalidad epistémica al señalar que el hablante es consciente de que lo que dice no es del todo exacto. Pues bien, el como que introduce estos CCM también tiene valor aproximativo, por lo que estos complementos de la variante c) nunca pueden entenderse como afirmaciones ciertas (algo que sí puede ocurrir con la variante con suplemento) sino que deben interpretarse como hipótesis subjetivas y falibles. Así, en un ejemplo como Huele a gasolina el enunciador puede estar seguro de su aserción o no, mientras que en Huele como a gasolina, el CCM siempre se entiende como algo dudoso (puede ser gasolina o cualquier otra sustancia).

En suma, oler es un verbo de percepción física que puede expresar todas las posibilidades lingüísticas de la tipología de Viberg. Existe una variante que expresa la percepción pura que podemos denominar oler-1 y otra que expresa la percepción olfativa activa, que sería oler-2. Estas dos variantes son transitivas, y se componen de un sujeto que puede ser un mero perceptor (oler-1) o un observador agentivo (oler-2), y de un objeto, que es el estímulo sensorial percibido. Naturalmente, la distancia semántica entre ambas variantes es difusa y reversible; así, algo que empieza siendo una percepción olfativa pura, puede convertirse en una percepción activa (percibimos un olor y nos concentramos después en él) y a la inversa (tras oler voluntariamente algo, lo ignoramos) (Fernández Jaén, 2006b).

Por su parte, puede llamarse oler-3 a la variante copulativa, variante de naturaleza intransitiva en la que hay un sujeto sintáctico que representa el estímulo, y que puede tener tres alternativas, en función de lo específico que sea el enunciador; si sólo indica la presencia de un olor se dará la variante a), y si desea especificar a qué huele el sujeto puede optar por las variantes b) o c), en función de lo seguro que esté de su afirmación ${ }^{10}$.

\subsection{Polisemia de oler}

Aparte de por su enorme versatilidad sintáctica, oler también se caracteriza por su potencial semántico, hecho que queda patente en su compleja polisemia. A continuación vamos a analizar todos los significados de oler, tanto físicos o perceptivos como no físicos o metafóricos. Para ello nos basaremos en la teoría cognitiva de la metáfora tal y como se presenta en la formulación de Lakoff y Johnson (1986); para estos autores, el ser humano utiliza su experiencia corporal para fundamentar su pensamiento abstracto, y es la metáfora el principal vínculo entre lo experiencial y lo cognitivo. De este modo, las experiencias físicas son la base conceptual en la que se apoyan las ideas abstractas, siempre y cuando la estructura básica del dominio fuente (lo físico) y del dominio destino (lo abstracto) sean esencialmente iguales, puesto que únicamente si ambas estructuras esquemáticas son similares pueden producirse las distintas proyecciones y correspondencias metafóricas, fenómeno que se denomina hipótesis de la invariabilidad (Turner, 1990).

10 También existen soluciones intermedias del tipo Huele como a pescado que indican normalmente baja modalidad epistémica. 
El verbo oler posee un total de doce significados, de los cuales cinco son físicos y siete son proyecciones metafóricas producidas a partir de los cinco primeros. Estos significados son los siguientes (Fernández Jaén, 2006b):

\begin{tabular}{|l|l|}
\hline \multicolumn{1}{|c|}{ Significados físicos } & \multicolumn{1}{c|}{ Significados no físicos } \\
\hline Percepción pura o PP (oler-1) & Significado D (sospechar, barruntar) \\
Percepción activa o PA (oler-2) & Significado E (averiguar, indagar) \\
Significado A (primera variante de oler-3) & Significado F (detectar, descubrir) \\
Significado B (segunda variante de oler-3) & Significado G (parecer, parecerse a) \\
Significado C (tercera variante de oler-3) & Significado H (sugerir, recordar) \\
& Significado I (ser algo malo, o parecerlo) \\
& Significado J (ser algo bueno, o parecerlo) \\
\hline
\end{tabular}

Tabla 5. Polisemia de oler.

Como se puede apreciar, las características fundamentales del olfato humano que analizamos antes hallan su reflejo en el tipo de significados abstractos que ha desarrollado oler a partir de sus cinco significados perceptivos. De los siete significados abstractos, tres se vinculan al dominio de la modalidad (D, E, F) y cuatro se relacionan con la naturaleza del sujeto $(G, H, I, J)$, pero lo que se constata es que lo que caracteriza a estos significados abstractos es su vaguedad referencial, su indeterminación y su falta de control, que son exactamente los rasgos prototípicos de los significados físicos de los que proceden.

La olfacción sensorial es percibida experiencialmente por el hablante, quien proyecta al dominio abstracto los mismos presupuestos básicos de dicha percepción para crear un significado más nocional (hipótesis de la invariabilidad). Así, el significado D es una proyección metafórica del significado de percepción pura (PP); de igual modo que podemos percibir de forma involuntaria un olor sin llegar a saber de qué olor se trata (vaguedad referencial) también podemos percibir un conocimiento o información, si bien con muy baja modalidad epistémica (una sospecha). Vemos un ejemplo a continuación:

(15) Me huelo que Rosa no va a venir.

El significado E posee modalidad deóntica (algo es necesario) y epistémica, y se basa en la percepción activa (PA); de la misma manera que podemos oler algo voluntariamente, podemos intentar obtener un conocimiento voluntariamente (averiguar). Lo que sucede es que, de igual modo que nunca podemos estar seguros de a qué huele algo por mucho que lo intentemos, el conocimiento que expresa $\mathrm{E}$ tampoco está asegurado, puesto que hacer averiguaciones no presupone obtener la información que se necesita, tal y como se muestra a continuación:

(15) Andrés ha intentado oler sus intenciones.

En cuanto al significado F, se basa también en la percepción pura (PP) aunque, en este caso, la modalidad epistémica es mayor con respecto a D. En ocasiones, percibimos involuntariamente un olor y sabemos con certeza de qué olor se trata; análogamente, podemos 
descubrir involuntariamente una información de forma objetiva, de modo que nuestro conocimiento aumenta, si bien de un modo no controlado (descubrir, detectar). Tenemos un ejemplo a continuación:

(16) El profesor olió el engaño de los alumnos.

El significado $G$, por su parte, se forma a partir de una proyección metafórica de los significados A, B y C, es decir, de las variantes copulativas. Ahora ya no hay un sujeto que percibe o intenta percibir metafóricamente un objeto (conocimiento abstracto), sino que en el predicado sólo aparece un sujeto del que se predica algo. Así, en el significado G se expresa que una realidad determinada (sujeto) se parece a otra, si bien se trata de una similitud subjetiva, puesto que la ausencia de objetividad que caracteriza a las percepciones olfativas (los olores nos recuerdan cosas de forma individual e intransferible) se mantiene con estos significados. En (17) se ofrece un ejemplo:

\section{(17) Eso que has dicho huele a mentira.}

Por lo que respecta al significado $H$, también se apoya en la estructura conceptual de los significados copulativos aunque, en este caso, el grado de modalidad epistémica es aún menor que en $\mathrm{G}$; con este significado se predica del sujeto que recuerda a algo y no que se aparece a algo, por lo que la vaguedad referencial y la subjetividad modal aumentan. Un olor puede activar una interpretación sensorial más física (Esta comida huele a verdura) o más indeterminada (Esta comida huele a buenos alimentos); estas dos posibilidades se transforman en el plano abstracto en los significados $\mathrm{G}$ y $\mathrm{H}$ respectivamente. Tenemos un ejemplo de $\mathrm{H}$ a continuación:

\section{(18) A mi la interpretación de esa actriz me huele a premio.}

Por último, los significados I y J, de esquema cognitivo casi idéntico, se construyen también a partir de los valores copulativos y poseen un valor muy específico: expresar que el sujeto sintáctico es o parece algo negativo o algo positivo. Como comentamos en el apartado 3. 1., una de las funciones más elementales del sentido del olfato en lo que a la supervivencia en el medio se refiere es la de avisar de la presencia de sustancias o fenómenos que no son convenientes. No obstante, también puede producirse la situación inversa, puesto que, como es sabido, la posesión de un olor agradable suele indicar que una determinada sustancia es saludable y beneficiosa. Pues bien, I y J son los significados que lexicalizan la contrapartida metafórica de estos dos valores; I expresa que una determinada realidad (sujeto) es o parece mala o sospechosa, mientras que $J$ expresa que el sujete parece ser positivo. Con todo, la modalidad epistémica en ambos casos es relativamente baja, puesto que de igual modo que el olfato nunca es un indicador definitivo, el conocimiento abstracto que deriva de él tampoco lo es. Ofrecemos a continuación ejemplos de estos dos valores:

(19) Este negocio me huele mal.

(20) Lo que he visto de mis nuevos vecinos me huele muy bien 
Por tanto, comprobamos que la hipótesis de la invariabilidad parece confirmarse en la polisemia del verbo oler. A partir de la información subjetiva que los hablantes poseen gracias a sus experiencias olfativas, se han creado una serie de proyecciones metafóricas a partir de todas las posibilidades de la olfacción sensorial que conservan la estructura conceptual básica del dominio origen. Por esta razón, oler ha desarrollado una serie de valores modales y cognitivos, si bien se trata de valores caracterizados por su baja modalidad epistémica, situación que diferencia notablemente al verbo oler de otros verbos de percepción como ver y oir, cuyos significados metafóricos son mucho más intelectivos ${ }^{11}$.

\section{Comportamiento pragmático de oler}

Todo lo expuesto hasta aquí atañe a los aspectos gramaticales y semánticos de oler. Hemos visto cómo cada construcción sintáctica constituye un significado diferente (distintas conceptualizaciones) y cómo los significados metafóricos se diseñan a partir de los significados físicos respetando sus imágenes esquemáticas, tal y como propone la lingüística cognitiva y la teoría de la metáfora de Lakoff y Johnson. Pero para obtener un conocimiento completo del comportamiento de nuestro verbo debemos examinar cómo funciona oler en el contexto de uso, puesto que según el modelo cognitivo la sintaxis, la semántica y la pragmática son inseparables y operan conjuntamente. Además, sólo atendiendo a los datos contextuales se puede determinar cuál es la conceptualización prototípica de oler, ya que en opinión de la escuela cognitivista todas las posibilidades expresivas de cada unidad de la lengua no son equivalentes, sino que hay algunas más prototípicas o centrales y otras más periféricas.

Para llevar a cabo esta interpretación, vamos a analizar un corpus de ocurrencias del verbo oler compuesto por un total de 1.770 oraciones contextualizadas procedentes de todo tipo de registros (científico, literario, etc. $)^{12}$, corpus gracias al cual podremos conocer el comportamiento de nuestro verbo en la comunicación real.

\subsection{El anclaje en el presente}

En el empleo real del lenguaje los verbos se conjugan de múltiples maneras, en función de las necesidades comunicativas de los hablantes. Sin embargo, la semántica de cada verbo impone una tendencias de uso que se pueden analizar empíricamente; por ejemplo, resulta lógico suponer que verbos como llegar o disparar tiendan a utilizarse en tiempos perfectivos puesto que aspectualmente estos verbos representan predicados resultativos de naturaleza télica (un fin), que normalmente se conciben como acciones totalmente terminadas (Vendler, 1967). Por tanto, aunque los contextos de habla son intrínsecamente ilimitados, los verbos propenden de forma natural a unos valores fundamentales.

11 I. Ibarretxe-Antuñano ha propuesta una explicación de los significados abstractos de los verbos de percepción denominada proceso de selección de propiedades (Ibarretxe-Antuñano, 1999, 2000, 2003). Según este planteamiento, cada sentido físico tiene un número finito de rasgos prototípicos de los que se seleccionan algunos en concreto en cada proyección metafórica. Por ejemplo, oler puede significar averiguar porque en esa proyección metafórica se seleccionan las propiedades prototípicas de la percepción activa [+voluntario] y [+detector] (Ibarretxe-Antuñano, 2000).

12 Hemos elaborado este corpus emplendo el CORDE (Corpus Diacrónico del Español) que se puede consultar en línea en la web www.http://corpus.rae.es. Para una descripción más detallada del corpus, consúltese Fernández Jaén (2006b: 553). 
A continuación ofrecemos una tabla con el número de ocurrencias de oler en todas las formas del modo indicativo y del modo potencial en nuestro corpus:

\begin{tabular}{|l|c|}
\hline Modo indicativo/potencial & Ocurrencias \\
\hline Presente & 602 \\
\hline Pretérito perfecto & 27 \\
\hline Pretérito imperfecto & 190 \\
\hline Pretérito pluscuamperfecto & 8 \\
\hline Pretérito indefinido & 139 \\
\hline Pretérito anterior & 0 \\
\hline Futuro imperfecto & 35 \\
\hline Futuro perfecto & 1 \\
\hline Condicional simple & 7 \\
\hline Condicional compuesto & 0 \\
\hline
\end{tabular}

Tabla 6. Frecuencia absoluta de ocurrencias en indicativo/potencial.

Estos resultados muestran que oler suele ser utilizado de un modo altamente motivado, ya que los usos más habituales se explican por la semántica que expresa.

Lo primero que se aprecia es que hay un predominio absoluto de ocurrencias en presente, lo que se explica por el fenómeno de la adaptación que mencionamos antes; los olores son percibidos por las personas durante pocos minutos, razón por la cual oler suele aparecer en las formas verbales que indican presente continuo.

Las formas de pasado aparecen mucho menos (valor más periférico), siendo las del pretérito imperfecto las más documentadas. Frente a las escasas ocurrencias en pretérito perfecto y pluscuamperfecto, el imperfecto se documenta en mayor medida debido a que expresa percepciones durativas acaecidas en el pasado, algo que se ajusta más a los significados habituales de oler; las percepciones olfativas son efimeras, y a causa de la vaguedad referencial que las caracteriza, normalmente no se recuerdan con facilidad y no se suele hacer referencia a ellas. Con todo, cuando oler se utiliza en pasado tiende a estar en imperfecto para representar el periodo de tiempo en que el estimulo olfativo podía percibirse, percepción que suele conceptualizarse aspectualmente como un estado durativo, como veremos después.

Aun así, como se observa en la Tabla 6., el pretérito indefinido supone una excepción puesto que aparece en el corpus 139 veces. No obstante, hay una explicación para esta contradicción aparente relacionada con la motivación semántica que impone el significado; el pretérito indefinido expresa acción en el pasado perfectiva y alejada del momento de enunciación, lo que se corresponde con una visión resultativa de la predicación. Esto significa que formas como oli u oliste denotan que el evento expresado por el verbo se concibe como una secuencia terminada y puntual (o logro), algo que sucede de forma total en un instante preciso del tiempo. Por ello, de las 139 ocurrencias 36 se corresponden con una percepción pura (PP) y 37 se vinculan al significado metafórico de descubrir, que son los dos valores semánticos que se expresan prototípicamente con un evento culminativo; la falta de control del olfato humano hace que las percepciones puras sean breves e involuntarias, algo que se corresponde con un logro, de igual modo que el significado de descubrir también es un logro involuntario 
(obtención espontánea de un conocimiento). Por ello, el 54,8\% de las ocurrencias del indefinido están motivadas semánticamente por tratarse de de casos de percepción pura (PP) o de ejemplos del valor $\mathrm{F}$ (detectar, descubrir), que son los significados que verbalizan eventos que se inician y se culminan de forma casi instantánea.

Con respecto a los tiempos en futuro y condicional, se comprueba fácilmente que son extremadamente periféricos, circunstancia que vuelve a explicarse por el fenómeno de la adaptación y por el resto de propiedades del olfato humano; la brevedad que caracteriza a las olfacciones y el hecho de que sea difícil prever un olor o establecer una hipótesis sobre él hacen que esos tiempos resulten extraños pragmáticamente.

Cabe señalar que eso no sucede con los verbos de percepción de la vista y del oído. Su significado altamente epistémico los habilita para proyectarse fácilmente hacia al futuro, como lo demuestran varios fenómenos, relacionados sobre todo con el verbo ver. Aparte de la existencia de la forma prefijada prever (ver con anterioridad) especializada en expresar un conocimiento previo en el tiempo, el verbo ver con su significado de saber se utiliza con mucha frecuencia en futuro, hasta el punto de que la estructura perifrástica a ver y la forma verbal verás se han gramaticalizado hasta convertirse en marcadores discursivos con múltiples valores (Montolío Durán y Unamuno, 2001; Chodorowska-Pilch, 2008).

Otra prueba muy interesante de la flexibilidad temporal de ver la hallamos en su frecuente aparición con el marcador discursivo ya. Según ha estudiado N. Delbecque (2006), ya es un marcador que sitúa la acción verbal en una base programática subyacente de carácter dinámico relacionada, fundamentalmente, con el paso del tiempo. Observemos las siguientes oraciones:

(21) Ya es miércoles.

(22) Laura ya ha cumplido doce años.

(23) Ya he leido el capitulo cuatro del libro.

En todas estas oraciones puede recuperarse un vector temporal implícito activado por el marcador ya. Así, la predicación de (21) se inserta dentro del ciclo temporal de los días de la semana; ya no sólo indica deícticamente el día en que se encuentra el enunciador, sino también su conciencia del transcurso mismo de los días. En (22) la edad se concibe como un proceso temporal por el que se va transcurriendo a medida que se cumplen años, mientras que en (23), gracias a este marcador, podemos inferir que el sujeto pretende leer el libro entero, puesto que ya sitúa la acción de leer en el guión temporal de la lectura completa del volumen. Esa inferencia, naturalmente, no se obtendría en un ejemplo como He leído el capitulo cuatro del libro, oración que no presupone la intención del sujeto de leer el libro entero.

Pues bien, como demuestra Delbecque (2006), es muy frecuente en español coloquial que ver con un significado intelectivo y en tiempos futuros vaya acompañado por $y a$, formando estructuras de alto valor epistémico como ya veremos, ya veréis, etc. Sin embargo, las construcciones similares con oler resultan extrañas, incluso con significados como descubrir o averiguar ${ }^{13}$ :

(24) \# Ya oleremos quién gana las elecciones.

(25) \# Ya oleré qué está tramando cuando vea sus informes.

13 No obstante, sí es frecuente la aparición de la partícula ya junto al verbo oler cuando éste está en presente o aparece en perífrasis verbales incoativas, del tipo Ya huele, Ya empieza a oler, etc. En estos casos ya introduce la 
También resulta interesante la frecuencia de aparición de ocurrencias en modo subjuntivo en nuestro corpus. La tabla siguiente muestra los datos:

\begin{tabular}{|l|c|}
\hline \multicolumn{1}{|c|}{ Modo subjuntivo } & Ocurrencias \\
\hline Presente & 197 \\
\hline Pretérito perfecto & 0 \\
\hline Pretérito imperfecto & 94 \\
\hline Pretérito pluscuamperfecto & 2 \\
\hline Futuro imperfecto & 18 \\
\hline Futuro perfecto & 0 \\
\hline
\end{tabular}

Tabla 7. Frecuencia absoluta de ocurrencias en subjuntivo.

Gracias a esta tabla se comprueba que el número de ocurrencias en subjuntivo desciende considerablemente con respecto al indicativo ${ }^{14}$. Esto resulta del todo lógico, teniendo en cuenta que este es el modo de lo potencial, de lo desiderativo, y la percepción de olores es un hecho que, como acabamos de comentar, no resulta fácil de enmarcar en este tipo de contextos. En cualquier caso, de nuevo son el presente y los pretéritos imperfectivos los tiempos más documentados ${ }^{15}$, lo que reafirma que la percepción olfativa suele relacionarse con el momento presente y con eventos imperfectivos.

Por último, mostramos a continuación el número de ocurrencias correspondientes a las formas no personales y ál imperativo morfológico de $2^{\mathrm{a}}$ persona del plural:

\begin{tabular}{|l|c|}
\hline Formas no personales / Imperativo & Ocurrencias \\
\hline Infinitivo simple & 220 \\
\hline Infinitivo compuesto & 1 \\
\hline Gerundio simple & 223 \\
\hline Gerundio compuesto & 3 \\
\hline Imperativo (oled) & 3 \\
\hline
\end{tabular}

Tabla 8. Frecuencia absoluta de ocurrencias de formas no personales y de imperativo.

presencia del olor en una secuencia temporal o guión subyacente (como preparar un plato de comida o realizar un experimento químico) con diversos momentos sucesivos, siendo la presencia de olor una evidencia de que dicho proceso está llegando a una determinada fase.

14 Es más, como se puede comprobar en Fernández Jaén (2006b), la mayoría de formas verbales de oler en subjuntivo no tienen ninguna ocurrencia documentada en todos los textos españoles que se encuentran en el CORDE.

15 Conviene aclarar que la gran mayoría de ocurrencias en presente de subjuntivo recogidas se refieren a las formas huela correspondientes a la $1^{\mathrm{a}}$ y $3^{\mathrm{a}}$ persona del singular, utilizadas en tratados médicos como imperativo sintáctico para indicar que alguien debe oler una determinada sustancia para sanar (Huela usted esa poción). Si prescindiéramos de esos tratados médicos el número de ocurrencias en subjuntivo descendería notablemente lo que aumentaria aún más el predominio de las formas en indicativo. 
Los datos no dejan lugar a dudas; las formas compuestas (de carácter perfectivo) tienen una mínima representación, mientras que el infinitivo y el gerundio simples están muy bien documentados, porque son formas que se relacionan fácilmente con el presente en multitud de estructuras, debido a su carácter atemporal y polivalente (infinitivo) e intrínsecamente durativo (gerundio). De nuevo, oler se ajusta a las formas verbales de lo inmediato. En cuanto al imperativo, su escasa aparición no resulta anómala puesto que la percepción activa (PA) es pragmáticamente inusual, lo que hace que sea infrecuente que se construya una orden con ella para varios individuos.

En definitiva, observamos que oler se conjuga prototípicamente en presente y en modo indicativo porque las olfacciones resultan breves (inicio y término en el momento de habla), y poco valiosas cognitivamente como para recordarlas en exceso o como para predecirlas en construcciones potenciales (oraciones condicionales, tiempo futuro). Pero aún queda otra cuestión por aclarar: ¿por qué los tiempos en pasado y en futuro son prototípicamente imperfectivos? El estudio del comportamiento sintáctico-semántico de nuestro verbo responderá esta pregunta.

\subsection{Prototipicidad sintáctico-semántica}

Ya conocemos los tiempos y modos más frecuentes en el uso de oler, pero aún falta por examinar cuáles son los significados prototípicos de este verbo y sus estructuras sintácticas más habituales. La siguiente tabla muestra estos datos ${ }^{16}$ :

\begin{tabular}{|l|l|l|}
\hline \multicolumn{1}{|c|}{ Significado } & \multicolumn{1}{c|}{ Ocurrencias } & \multicolumn{1}{c|}{ Porcentaje } \\
\hline PP (percepción pura) & 223 & $13 \%$ \\
\hline PA (percepción activa) & 307 & $17,9 \%$ \\
\hline A (variante 1 de oler-3) & 450 & $26,2 \%$ \\
\hline B (variante 2 de oler-3) & 304 & $17,7 \%$ \\
\hline C (variante 3 de oler-3) & 30 & $1,7 \%$ \\
\hline D (sospechar, barruntar) & 58 & $3,3 \%$ \\
\hline E (averiguar, indagar) & 10 & $0,5 \%$ \\
\hline F (detectar, descubrir) & 109 & $6,3 \%$ \\
\hline G (parecer, parecerse a) & 35 & $2 \%$ \\
\hline H (sugerir, recordar) & 167 & $9,7 \%$ \\
\hline I (ser algo malo, o parecerlo) & 20 & $1,1 \%$ \\
\hline J (ser algo bueno, o parecerlo) & 1 & $0,05 \%$ \\
\hline
\end{tabular}

Tabla 9. Frecuencia absoluta y relativa de los significados de oler.

16 Hay que señalar que en lo que al contenido semántico se refiere sólo hemos trabajado con 1.714 ocurrencias; las otras 56 se han descartado por tratarse de ejemplos descontextualizados de los que no se podía extraer el significado. 
Lo primero que se observa al examinar estos datos es que las variantes de oler-3 son las más frecuentes (sobre todo la A) puesto que constituyen el 45,7\% del corpus. Por tanto, vemos que el significado prototípico de oler es el de la percepción copulativa en la que el sujeto sintáctico es el olor mismo. El hecho de que el prototipo sea de naturaleza estativa explica la tendencia de este verbo a conjugarse en tiempos imperfectivos; los eventos de estado al no ser acciones en sentido estricto, se conceptualizan como eventos continuos en el tiempo, significado que se expresa lingǘsticamente con los tiempos imperfectivos en los que no hay delimitados un principio y un final (Vendler, 1967). Los olores suceden (huelen) o bien en presente o bien en pasado, pero de forma durativa.

También queda patente que el lenguaje está fuertemente corporeizado puesto que el prototipo semántico oler-3 (significados $\mathrm{A}, \mathrm{B}$ y C) refleja las propiedades fisiológicas de nuestro olfato. Los seres humanos no podemos controlar fácilmente las percepciones olfativas, ni podemos retenerlas (adaptación) ni podemos analizarlas con exactitud o determinar la fuente con total precisión. Todos esos rasgos explican no sólo la tendencia al presente, a lo imperfectivo y a lo real (modo indicativo) sino también el diseño sintáctico de las conceptualizaciones prototípicas; lo más frecuente en el empleo de oler es utilizar una estructura en la que la existencia del sujeto-estímulo es lo más importante, quedando el perceptor en un segundo plano ${ }^{17}$, como mero enunciador de una percepción que entiende que es totalmente independiente de él. De este modo, la construcción prototípica de oler constituye la formulación psicolingüística de la percepción olfativa humana ${ }^{18}$.

La vaguedad referencial, a su vez, también explica el hecho de que de las tres variantes de oler-3 sea la A (sin complementos) la más frecuente. No podemos determinar con facilidad a qué huelen las cosas por lo que en el uso cotidiano de nuestro verbo nos limitamos a indicar la existencia misma del olor, siendo más frecuente no lanzar una hipótesis en forma de suplemento o de CCM acerca del tipo de olor que hacerlo. Por ello, el prototipo de oler constituye un evidencial de evidencia directa pero de baja modalidad epistémica, lo que demuestra que no toda percepción sensorial conduce siempre a un conocimiento objetivo.

En cuanto a los valores metafóricos, puede afirmarse que son muy periféricos, lo que indica que oler es un verbo fuertemente vinculado a lo físico y perceptivo. Además, de los valores abstractos son $\mathrm{F}$ (descubrir) y $\mathrm{H}$ (recordar) los más frecuentes; de este modo, se constata que incluso en el plano abstracto oler tiende a la involuntariedad del conocimiento (descubrir) y a la falta de certeza de las impresiones (sugerir). Por último, no resulta extraño que el significado más periférico en la conceptualización de oler sea el J (ser algo bueno), habida cuenta de que el olfato favorece siempre la detección de estímulos negativos en lugar de positivos, fenómeno que queda plasmado incluso en los contenidos metafóricos de nuestro verbo.

En definitiva, el verbo oler tiene un significado prototípico físico y estativo de carácter intransitivo, algo que lo diferencia considerablemente de otros verbos de percepción. Habi-

17 En ocasiones el perceptor queda representado en la estructura por un pronombre personal átono: Me huele mal la comida.

18 Conviene reseñar que esta vaguedad se manifiesta incluso en muchas ocurrencias transitivas de percepción pura y activa, ya que en nuestro corpus son muy abundantes los ejemplos de acusativos internos del tipo Olí un olor. Como vemos, incluso cuando el perceptor es el sujeto y el estímulo el complemento directo no está asegurada la certeza acerca de qué se está oliendo, puesto que los acusativos internos se caracterizan por su naturaleza tautológica y pleonástica. 
tualmente los verbos de visión, de audición y de otros sentidos aparecen en estructuras transitivas con sujeto-observador y objeto percibido, que serían su prototipo (García-Miguel, 2005). Sin embargo, oler no se comporta prototípicamente de ese modo ya que en su caso el flujo de energía (Langacker, 1987) no suele ir del observador (sujeto) al estímulo (complemento directo), sino del estímulo (sujeto) al perceptor o paciente (enunciador pasivo) ${ }^{19}$.

\section{Conclusiones}

Parece claro que la tesis de que el lenguaje humano está corporeizado es muy pertinente en la investigación lingüística ya que multitud de fenómenos no podrían explicarse satisfactoriamente sin atender a las propiedades de nuestro cuerpo, que son el nexo fundamental entre el mundo y nuestro pensamiento. En este trabajo hemos analizado la expresión lingüística del olfato que materializa el verbo oler, y hemos comprobado que las propiedades biológicas del olfato humano pautan la configuración sintáctico-semántica de este verbo y su utilización en los contextos de habla.

Como evidencial, oler demuestra que no todas las percepciones físicas directas tienen un alto grado de modalidad epistémica. La falta de agudeza del olfato humano impide saber con seguridad qué se está oliendo, razón por la cual los complementos de este verbo indican habitualmente falta de certeza. Ahora bien, las evidencias directas del olfato no son desdeñables puesto que han jugado un papel interesante en nuestra evolución. Gracias al olfato detectamos la presencia de peligros, de sustancias tóxicas o de cualquier otro elemento que se debe evitar, de manera que los olores pueden servir para obtener conclusiones o para establecer hipótesis (alguien ha cocinado algo, ha habido un incendio y queda olor a quemado, etc.). Por ello, creemos que la división de Willett entre evidencias directas y evidencias indirectas es demasiado discreta, puesto que la casuística es mucho más compleja que la mera ecuación percepción directa igual a conocimiento fiable y percepción indirecta igual a conocimiento contingente; una percepción directa puede servir para hacer un razonamiento indirecto, de igual modo que una evidencia reproducida puede ser igual de fiable que algo que se percibe directamente.

También hemos comprobado que la idea de construcción y de conceptualización que defiende la lingüística cognitiva explica perfectamente el funcionamiento de oler. Las propiedades del olfato humano (brevedad, falta de control, vaguedad referencial) quedan de manifiesto en la vida cotidiana (contexto pragmático) y quedan reflejadas tanto en la semántica (valores metafóricos de modalidad epistémica variable) como en la sintaxis, que propende a los tiempos en presente, con valor estativo y modo indicativo (reflejo lingüístico de la conciencia corpórea).

Por todo lo expuesto, pensamos que la pragmática y la lingüística cognitiva son disciplinas científicas que permiten analizar el lenguaje humano de un modo integral, debido a su firme planteamiento de que la corporeidad, la subjetividad de los hablantes, la sintaxis, la semántica y el uso cotidiano de la lengua forman un todo en el que cada elemento influye decisivamente en todos los demás.

19 Estas estructuras también existen con verbos de percepción visual y de otros tipos, si bien con esos sentidos son muy periféricas. Para un análisis tipológico de esas estructuras con verbos de percepción visual consúltese el trabajo de Horno Chéliz (en prensa). 


\section{Referencias bibliográficas}

Barnes. J. (1984): "Evidentials in the Tuyuca verb", Internacional Journal of American Linguistics, 50 , págs. $255-271$.

Boisson, C. (1997): "La dénomination des odeurs: variations et régularités linguistiques", Intellectica, 24 , págs. $29-49$.

Bybee, J., L. R. Perkins y W. Pagliuca (1994): The evolution of grammar: tense, aspect and modality in the languages of the world. Chicago, University of Chicago Press.

Chodorowska-Pilch, M. (2008): "Verás in Peninsular Spanish as a grammaticalized discourse marker invoking positive and negative politeness", Journal of Pragmatics, 40, págs. 1357-1372.

Classen, C. (1993): Worlds of Sense. Exploring the Senses in History and across Cultures. London/ New York, Longman.

Classen, C., D. Howes y A. Synnott (1994): Aroma. The Cultural History of Smell. London/ New York, Routledge.

Croft, W. (2001): Radical construction grammar: Syntactic theory in typological perspective. Oxford, Oxford University Press.

Danesi, M. (1985): “The metaphorical extensión of vision: a linguistic universal?", Geolinguistics, II, págs. $1-12$.

Danesi, M. (1990): "Thinking is seeing: visual metaphors and the nature of abstract thought", Semiotica, $80,3 / 4$, págs. $221-237$.

Delbecque, N. (2006): "Ya: aclaración cognitiva de su uso y función”, Revista Española de Lingüística, 36, Fasc. 1, págs. 43-72.

Dendale, P. y L. Tasmowski (2001): "Introduction: evidentiality and related notions", Journal of Pragmatics, 33,3 , págs. 339-348.

Evans, N. y D. Wilkins (2000): "In the mind's ear: The semantic extensions of perception verbs in Australian languages", Language, 76-3, págs. 546-592.

Fernández Jaén, J. (2006a): "Verbos de percepción sensorial en español: una clasificación cognitiva", Interlingüistica, 16, págs. 1-14.

Fernández Jaén, J. (2006b): "Análisis cognitivo del verbo oler". En Actas del XXXV Simposio de la SEL, León, Universidad de León, págs. 542-561.

García-Miguel, J. M. (2005): “Aproximación empírica a la interacción de verbos y esquemas construccionales, ejemplificada con los verbos de percepción”, ELUA, 19, págs. 169-191.

Givón, T. (1991): "Isomorphism in the grammatical code: cognitive and biological considerations", Studies in Language, 15, 1, págs. 85-114.

Goldberg, A. (1995): Constructions: a construction grammar approach to argument structure. Chicago, Chicago University Press.

Haiman, J. (1980): "The Iconicity of Grammar: Isomorphism and Motivation", Language, 56-3, págs. $515-540$.

Haiman, J. (1985): Natural syntax. Iconicity and erosion. Cambridge, Cambridge University Press.

Horno Chéliz, M. C. (en prensa): "La interpretación estativa de la percepción visual desde un punto de vista tipológico". En Actas del VIII Congreso de Lingüística General, Edición CD-Rom.

Ibarretxe-Antuñano, I. (1999): "Metaphorical mappings in the sense of smell". En Gibbs, R. y G. Steen (eds.): Metaphor in Cognitive Linguistics. Amsterdam, John Benjamins, págs. 29-45.

Ibarretxe-Antuñano, I. (2000), “Es la metáfora el único proceso que interviene en el cambio semántico?”. En Maldonado, R. (ed.): Revista Española de Lingüística Aplicada. Volumen Monográfico. Logroño, Mogar Linotype, págs. 409-418.

Ibarretxe-Antuñano, I. (2003): "El cómo y el porqué de la polisemia de los verbos de percepción". En Molina, C. et alii. (eds.): Cognitive Linguistics in Spain at the turn of the century. Madrid, Universidad Autónoma de Madrid, págs. 213-228. 
Ibarretxe-Antuñano, I. (2008): "Vision Metaphors for the Intellect: Are they Really Cross-Linguistic?", Atlantis. Journal of the Spanish Association of Anglo-American Studies, 30.1, págs. 15-33.

Johnson, M. (1987): The body in the mind: The Bodily Basis of Meaning, Imagination, and Reason. Chicago, University of Chicago Press.

Korsmeyer, C. (2002): El sentido del gusto. Comida, estética y filosofia. Barcelona, Paidós.

Lakoff, G. y M. Johnson (1986): Metáforas de la vida cotidiana. Madrid, Cátedra.

Langacker, R. W. (1987): Foundations of cognitive grammar Vol. I. Theoretical Prerequisites. Stanford, Stanford University Press.

Langacker, R. W. (1991): Foundations of cognitive grammar Vol. II. Descriptive Application. Stanford, Stanford University Press.

Lazard, G. (2001): On the grammaticalization of evidentiality", Journal of Pragmatics, 33, 3, págs. 359-368,

Luque Durán, J. de D. (2001): Aspectos universales y particulares del léxico de las lenguas del mundo. Granada, Método.

Matlin, M. W. y H. J. Foley (1996): Sensación y percepción. México, Prentice-Hall Hispanoamericana.

Montolío Durán, E. y V. Unamuno (2001): "The discourse marker a ver (Catalan, a veure) in teacherstudent interaction", Journal of Pragmatics, 33, págs. 193-208.

Moreno Cabrera, J. C. (2003): Semántica y gramática. Sucesos, papeles semánticos y relaciones sintácticas. Madrid, Antonio Machado Libros.

Mosterín, J. (2006): La naturaleza humana. Madrid, Espasa Calpe.

Moure, T. (2001): Universales del lenguaje y linguo diversidad. Barcelona, Ariel.

Otaola, C. (1988): "La modalidad (con especial referencia a la lengua española)", Revista de Filología Española, LXVIII, 1, 2, págs. 97-117.

Plungian, V. A. (2001): "The place of evidentiality within the universal grammatical space", Journal of Pragmatics, 33, 3, págs. 349-358.

Pustejovsky, J. (1991): The Syntax of Event Structure". En Levin, B. y S. Pinker (eds.), Lexical and Conceptual Structure. Oxford, Blackwell, págs. 47-81.

Pustejovsky, J. (1995): The Generative Lexicon. Cambridge, Mass., MIT Press.

Ruiz Gurillo, L. (2006): Hechos pragmáticos del español. Alicante, Universidad de Alicante.

Sweetser, E. (1990): From etymology to pragmatics. Metaphorical and cultural aspects of semantic structure. Cambridge, Cambridge University Press.

Turner, M. (1990): "Aspects of the invariance hypothesis", Cognitive Linguistics, 1.2, págs. 247-255.

van Valin, Jr. R. D. y R. J. LaPolla (1997): Syntax. Structure, Meaning and Function. Cambridge, Cambridge University Press.

Vendler, Z. (1967) Linguistics in Philosophy. Ithaca, Cornell University Press.

Viberg, A. (1984): "The verbs of perception: a typological study". En Butterworth, B. et alii (eds.): Explanations for language universals. Berlin, Mouton, págs. 123-162.

Willett, T. (1988): "A Cross-Linguistic Survey of the Grammaticization of Evidentiality", Studies in Language, 12, págs. 51-97. 